УДК 378

\title{
АНИМАЦИЯ ДЛЯ ОБРАЗОВАТЕЛЬНОГО КОНТЕНТА СРЕДСТВАМИ РOWЕRPOINT
}

\author{
Ван Инжуй \\ Аветисян Джавад Давидович \\ к.т.н., профессор \\ Научный руководитель: Катханова Юлия Федоровна \\ д.П.н., профессор
}

ВГБОУ ВО «Московский педагогический государственный университет»

Аннотация: В статье рассмотрено, как анимация, созданная с помощью программы PowerPoint, может стать эффективным компонентом самостоятельно разработанного электронного образовательного ресурса. Использование анимации в процессе обучения повышает интерес и мотивацию учащихся к учению, преподносит изучаемый материал в более доступной для понимания форме. Следует отметить, что у преподавателя всегда имеется много методов обучения. Однако анимация может стать эффективным приемом активного вовлечения обучающихся в образовательный процесс, если она соответствует всем требованиям дидактики. Причем, плохо разработанная анимация может отвлечь учащегося от важных компонентов учебного материала. А вот правильная анимация может усилить восприятие изучаемых идей и концепций, создавая высококачественную образовательную среду. Особой популярностью у педагогов при создании образовательного ресурса у большинства преподавателей пользуется программа PowerPoint, в основном за простоту работы с этим приложением, за легкость управления, за интеграцию с мультимедиа, а также за легкость модификации. Тем не менее не все разработчики-педагоги хорошо знакомы с функциями PowerPoint и его возможностями при создании современного образовательного ресурса. Как правило, содержание учебного курса ограничено размещением на слайдах текста и иллюстративного материала, а функция анимации в PowerPoint почти не используется. Учитывая вышесказанное, в данной статье предлагается методический материал по освоению функций PowerPoint, с помощью которых можно получить анимацию, обогатив визуализацию учебной информации, повысив уровень ее усвоения обучающимися. Наконец, мы можем утверждать, 
что анимация, созданная с помощью PowerPoint проста, практична и заслуживает особого внимания разработчиков цифровых образовательных ресурсов.

Ключевые слова: PowerPoint, Smartart, онлайн-курс, анимация, презентация, траектория движения, контент.

\title{
ANIMATION FOR EDUCATIONAL CONTENT POWERPOINT
}

\section{Wang Yingrui \\ Avetisyan Javad Davidovich Academic Supervisor: Katkhanova Yulia Fedorovna}

\begin{abstract}
The article discusses how animation created using PowerPoint can become an effective component of a self-developed electronic educational resource. The use of animation in the learning process increases the interest and motivation of students to learn, presents the studied material in a more understandable form. It should be noted that the teacher always has many teaching methods. However, animation can become an effective technique for actively involving students in the educational process if it meets all the requirements of didactics. Moreover, poorly designed animation can distract the student from important components of the educational material. On the other hand, the right animation can enhance the perception of the ideas and concepts being studied, creating a high-quality educational environment. The PowerPoint program is especially popular among teachers when creating an educational resource for most teachers, mainly for the simplicity of working with this application, for its ease of management, for integration with multimedia, and also for the ease of modification. However, not all educational developers are familiar with PowerPoint's features and capabilities to create a modern educational resource. Typically, curriculum content is limited to text and illustrations on slides, and PowerPoint's animation function is almost never used. Considering the above, this article offers methodological material on mastering the functions of PowerPoint, with the help of which you can get animation, enriching the visualization of educational information, increasing the level of its assimilation by students. Finally, we can argue that PowerPoint animations are simple, practical, and deserve the special attention of digital education developers.
\end{abstract}

Key words: PowerPoint, SmartArt, online course, animation, presentation, trajectory, content. 


\section{Анимация PowerPoint, как способ создания онлайн-курсов.}

В наше время компьютерная анимация широко используется в индустрии кино, а также в мультипликационных студиях. C ее помощью компьютерные художники оживляют фантастических персонажей, создают невероятные миры. Причем, в подготовке сценария задействуются актёры в специальных костюмах с лампочками, которые записываются на видео и анализируются специальным программным обеспечением. Итоговые данные о перемещении суставов и конечностей актёров применяют к трёхмерным скелетам виртуальных персонажей, чем добиваются высокого уровня достоверности их движения.

Анимация записывается специальным оборудованием с реально двигающихся объектов и переносится на их имитацию в компьютере. Создано огромное разнообразие очень сложного программного обеспечения: Adobe Animate, Toon Boom Harmony, Moho, Pencil2D, TupiTube, Synfig Studio, Pivot Animator, OpenToonz, Cinema 4D. Однако ни по стоимости создания, ни по подготовленности преподавателей вузов, которые могут быть разработчиками мультимедийного интерактивного онлайн-курса (МИОК) по своим дисциплинам все последние достижения цифровых технологий не подходят для разработки современных МИОК, которые сегодня используются в дистанционном или смешанном обучении [1]. Поэтому необходимо найти такой инструмент для создания анимации, который был бы доступен для преподавателей. К таким инструментам авторы данной статьи относят последнюю версию PowerPoint (2016), который достаточно прост для освоения пользователями и насыщен большими возможностями для реализации любых идей и концепций.

\section{Обзор анимации в PowerPoint.}

Обратим внимание на то, что начиная с 2003 в PowerPoint добавлены эффекты «Выделение», «Выход» и «Путь действия» (включая рисование настраиваемых путей для перемещения изображения. В частности, эффект «Рисование настраиваемого пути» может заставить объект перемещаться по настраиваемому пути.

Вы можете попробовать. Скомбинируйте эффекты «Нарисовать собственный путь» и эффекты «Масштаб» и «Градиент» на выходе, и пусть воздушный шар медленно поднимется на одном слайде $\rightarrow$ поплывет на расстояние $\rightarrow$ еще и подробнее «Маленький» $\rightarrow$ все более и более туманный. Вся анимация была сделана за один раз, и процесс прошел гладко. Для режима анимации PowerPoint также добавили две новые функции «До (из предыдущего пункта)» и «Запуск анимации» для управления изображением. 
Используя метод анимации «До», можно установить эффект одновременного запуска анимации нескольких объектов на одном слайде. Причем, время начала анимации для различных объектов можно установить самостоятельно. В добавок анимация прокручивающихся титров, созданная в версии 2003, позволит читать большие абзацы текста один за другим, а синхронизация анимации и музыки (звука) уже не будет сложной задачей.

\section{Типы анимации в PowerPoint.}

B PowerPoint есть четыре типа анимационных эффектов: вход, выделение, выход и траектории движения. Они отражают точку, в которой необходимо, чтобы анимация произошла (рис. 1).

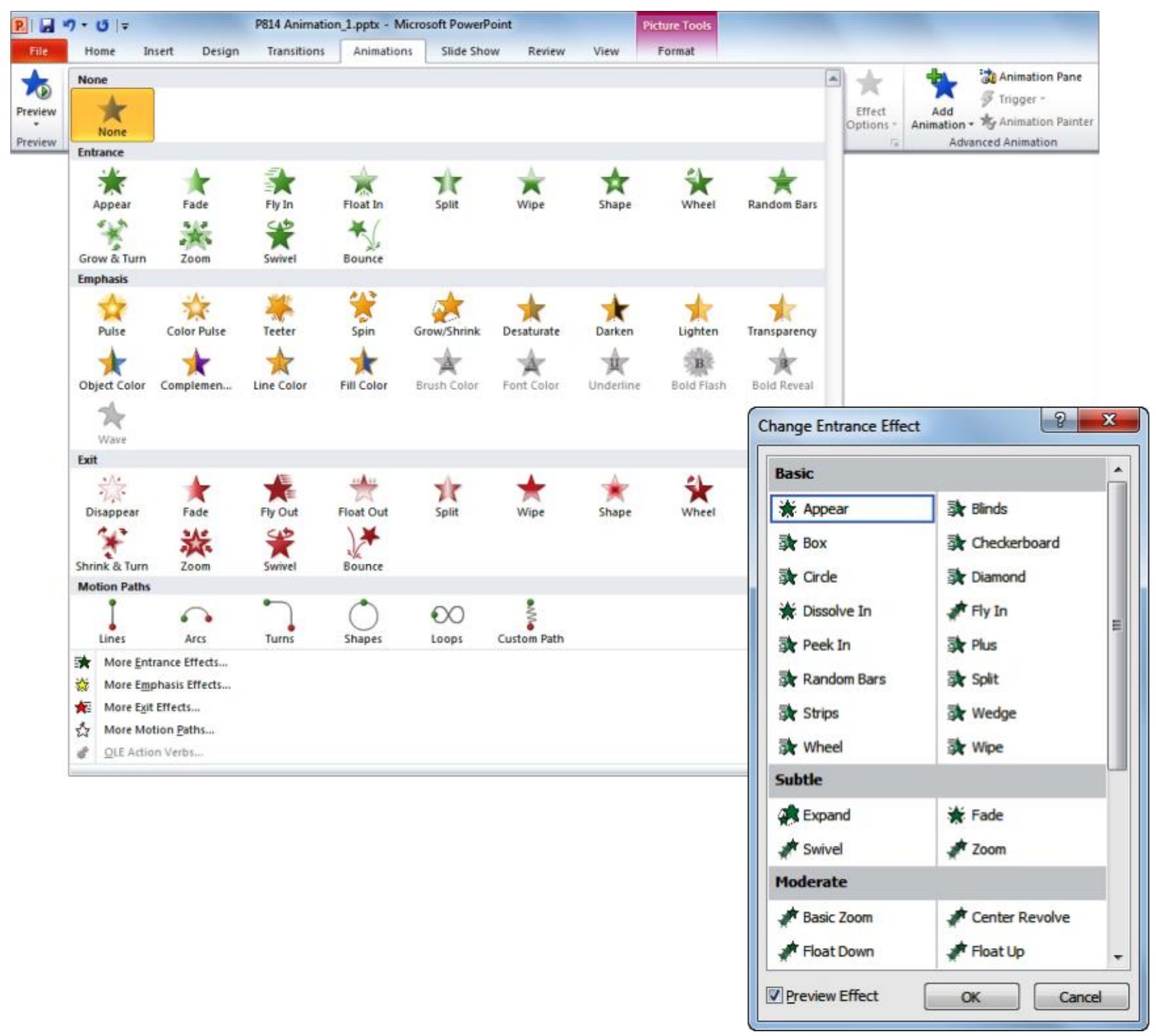

Рис. 1. Четыре типа анимационных эффектов в PowerPoint 
Вход: эффекты входа определяют способ отображения объектов на слайде. Например, отдельные строки текста могут вылетать сбоку от слайда или названия слайдов постепенно исчезают по мере отображения слайдов.

Акцент: эффекты акцента управляют тем, как взгляд аудитории будет обращен на анимированный объект. Например, можно заставить изображение пульсировать или вращаться или заставить строку текста двигаться в форме волны.

Выход: эффекты выхода определяют, как анимированные объекты будут покидать слайд. Например, изображение может отскочить или сжаться, и слайд может исчезнуть.

Пути движения: пути движения управляют перемещением текста или объектов по слайду. Например, можно заставить объекты двигаться вверх или вниз, двигаться в определенном направлении или даже создать свой собственный путь, по которому объект будет следовать.

Если не получилось найти требуемый эффект анимации в галерее, можно отобразить всю коллекцию эффектов каждого типа (например, вход или выход), выбрав параметр в нижней части галереи, чтобы открыть диалоговое окно «Изменить эффекты». (см. рис. 1 справа). В этом случае эффекты анимации сгруппированы в соответствии с воздействием эффекта - Базовый, Тонкий, Умеренный и Захватывающий, а для траекторий движения Базовый, Линии и кривые и Специальный.

\section{Обзор анимации PowerPoint.}

Мультимедийное программное обеспечение стало неотъемлемой частью сегодняшнего процесса преподавания и обучения. «Статичными иллюстрациями в современном мире сложно кого-то удивить и заинтересовать. Поэтому педагог, использующий в своей практике анимацию, лучше овладевает вниманием обучающихся, эффективней передает информацию, увеличивает вовлеченность обучающихся, повышает интерес к учению, одновременно используя эту технологию для развития творческого потенциала студентов» [2, с. 63]. Безусловно, существует множество интерактивных мультимедийных программ. Однако PowerPoint сегодня является одной из наиболее широкодоступных и используемых программ. Исследования показали, что студенты находили лекции в формате PowerPoint более интересными, чем традиционные. Итак, каковы преимущества анимации PowerPoint в образовании?

\section{Анимация может заинтересовать студентов.}

Использование анимации становится все более распространенной во многих образовательных презентациях. Она более эффективна, чем статичные 
последовательно расположенные изображения. При правильном исполнении анимация может привлечь и поддержать интерес ко всей презентации, а по сравнению со статичной, анимированная графика более понятна, информативна и ближе к характеристикам изучаемого объекта. Анимация в PowerPoint можно использовать в качестве мульти модальной информации в качестве продвинутого органайзера для представления контента обучающимся, для преобразования аудиовизуальных материалов, диаграмм и графических элементов к определенному изображению и идее или замыслу [3]. Большинство студентов считают, что лекции с использованием анимации более интересны и привлекательны, чем традиционные лекции. Поэтому преподаватель постоянно должен улучшать и совершенствовать динамичные и интерактивные презентации.

\section{Пользовательские анимации PowerPoint}

Создание анимации в PowerPoint, содержащей несколько мультимедийных элементов, включая текст, графику и звук, может добавить интерес и азарт учащимся, изучающим конкретный учебный материал. Причем, функция настраиваемой анимации в PowerPoint предоставляет список эффектов, которые пользователи могут применять к таким объектам, как изображения, текст и другую графику, чтобы анимировать их вовремя слайдшоу. Независимо от того, добавляет ли пользователь музыкальное сопровождение для создания определенного настроения или различные звуковые эффекты для усиления ключевых моментов, они еще больше привлекут внимание аудитории и улучшат восприятие учебного материала (рис. 2).

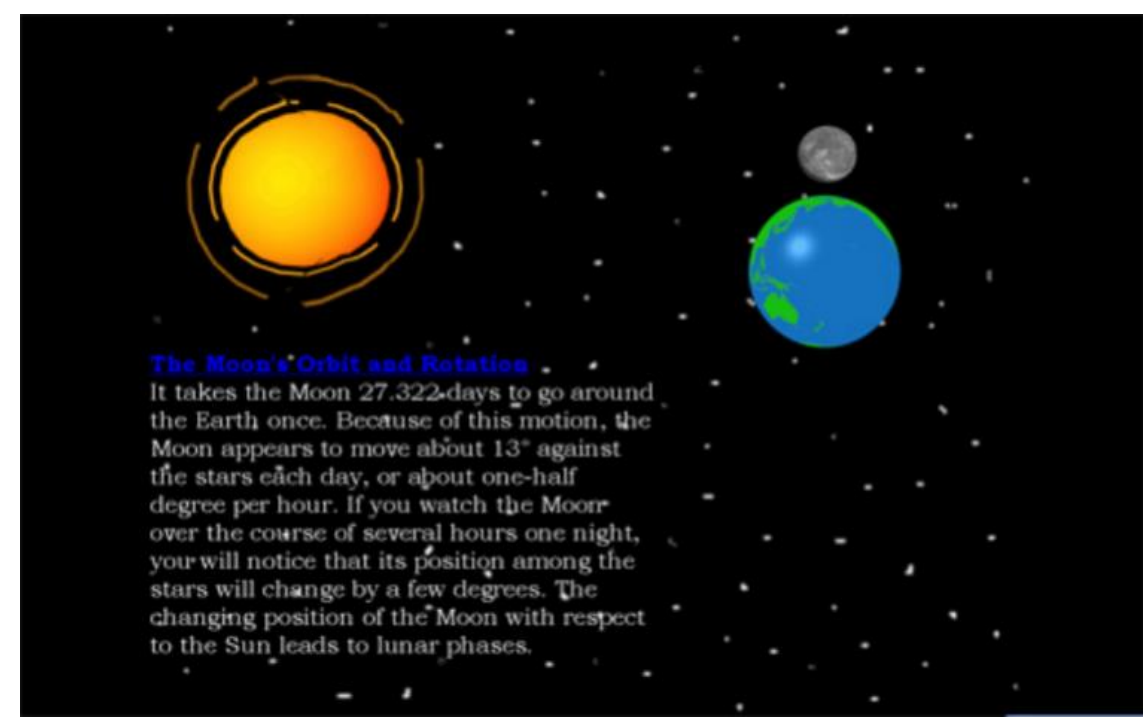

Рис. 2. Слайд PowerPoint с ключевыми элементами 


\section{Создание анимации в PowerPoint.}

PowerPoint имеет более 100 предустановленных анимаций и еще больше тех, которые можно настроить с помощью путей движения. На панели задач «Настраиваемая анимация» есть четыре основных категории эффектов для усиления концепции. Эти эффекты включают в себя вход, выделение, выход и траектории движения (на рис. 3 показан пример анимированной викторины о Луне в PowerPoint).

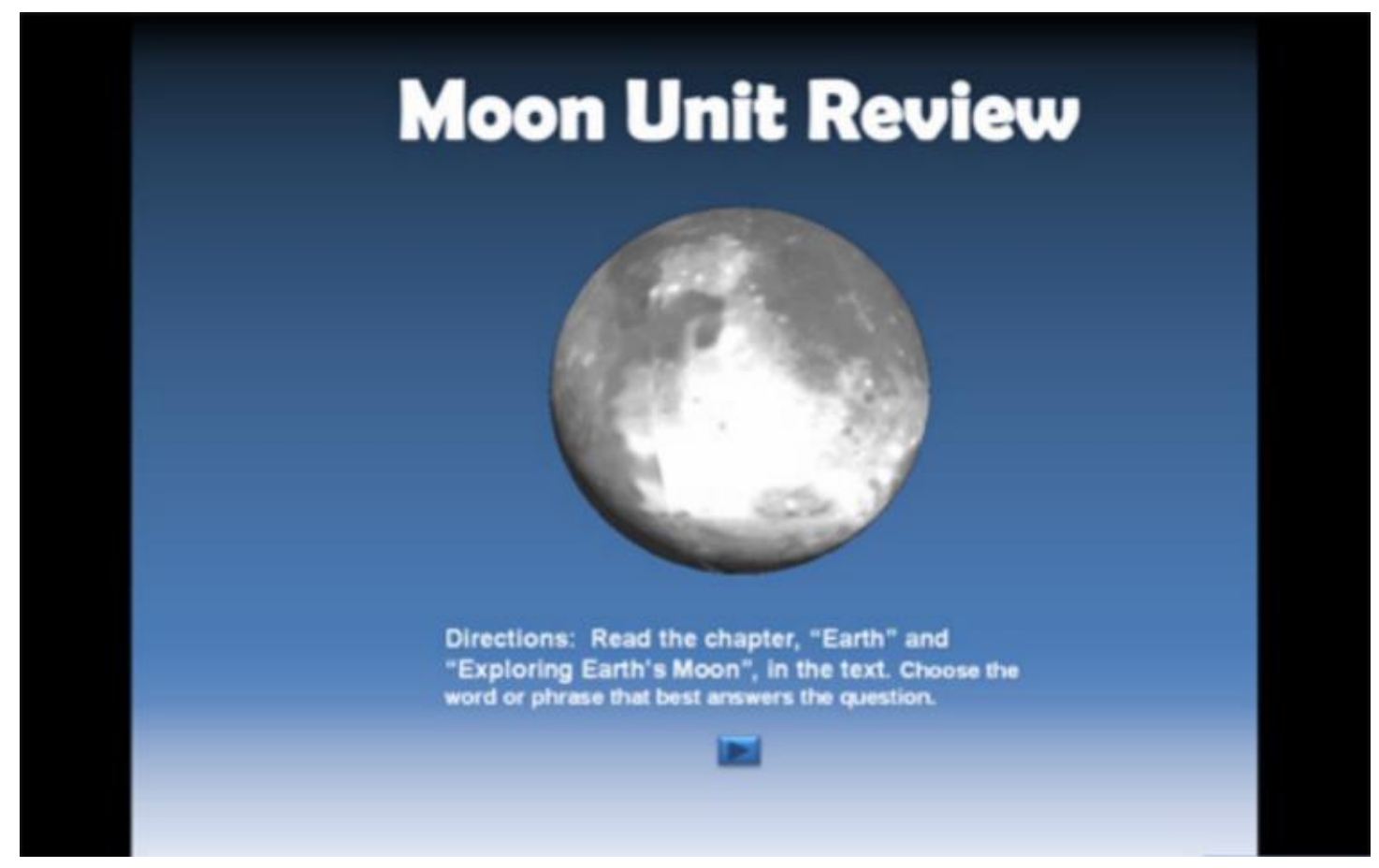

Рис. 3. Луна в викторине о луне

Следует заметить, что создание анимации требует некоторой практики в работе с эффектами. Есть несколько отличных сайтов анимации PowerPoint, например, PowerPoint Heaven, который демонстрирует и предлагает учебные пособия по анимации PowerPoint. Отметим, что анимация может не только помочь сделать презентацию более динамичной. Ее можно использовать для эффективного управления потоком информации. Например, можно анимировать каждую точку текста, чтобы она появлялась, когда вы будете говорить об этом, а аудитория будет слушать, не отвлекаясь на оставшуюся на слайде информацию (рис. 4). 


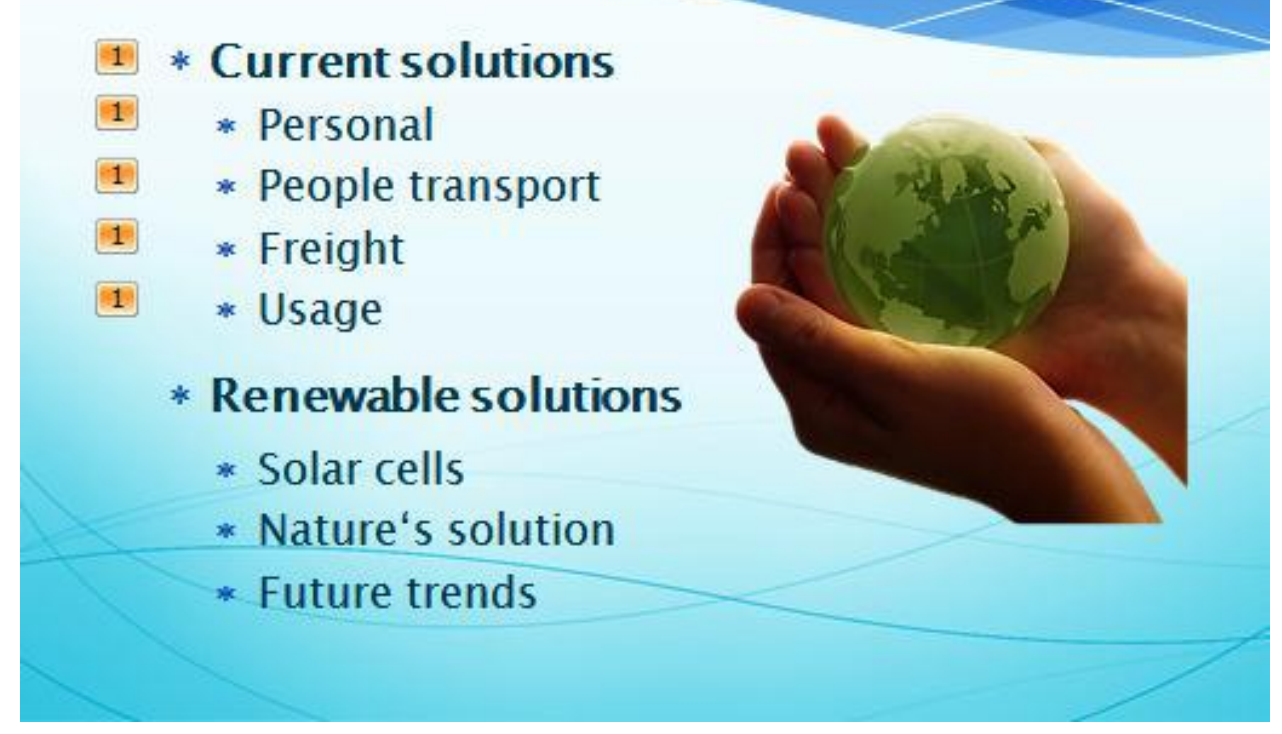

Рис. 4. Анимационный текст

\section{Анимационные объекты.}

Помимо анимации текста, можно применять анимацию к объектам, чтобы подчеркнуть свою идею или привлечь внимание аудитории. Однако можно и переборщить с анимацией в презентации. Слишком много анимации может отвлекать слушателя, а надо, чтобы студенты уходили, вспоминая содержание лекции, а не потрясающую анимацию (рис. 5).

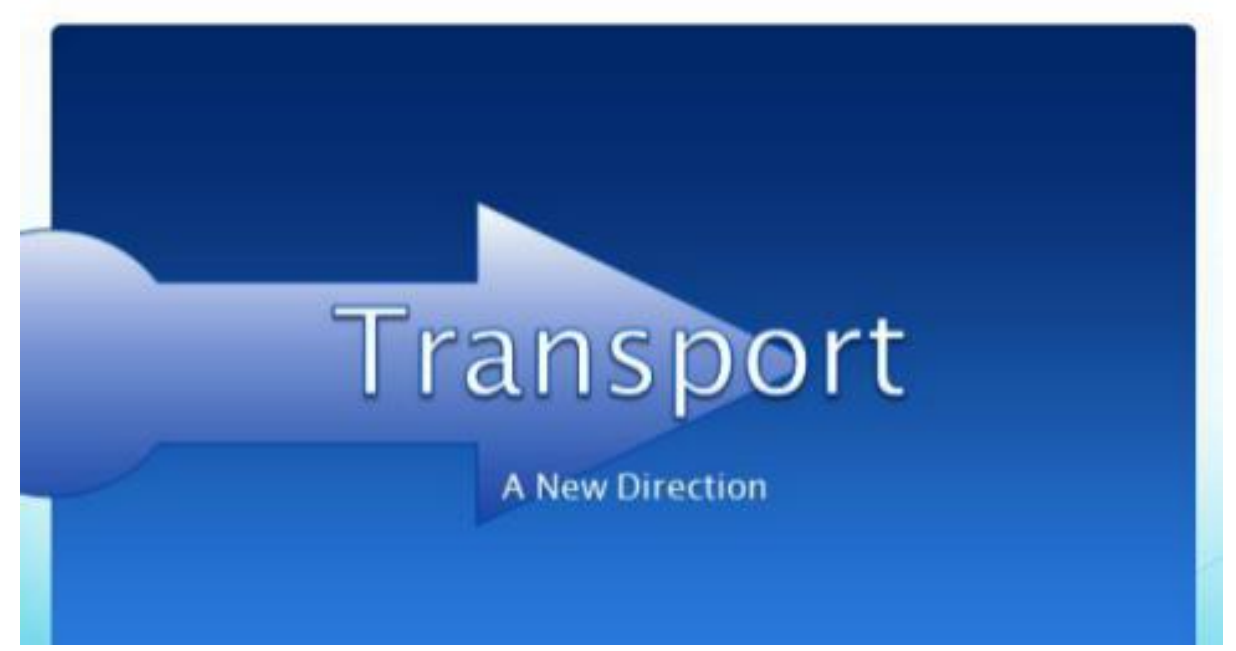

Рис. 5. Анимационные объекты

\section{Применение нескольких эффектов.}

К одному и тому же объекту можно применить несколько эффектов. Однако если выбирается второй эффект из галереи анимации, то он просто заменит первый, примененный к объекту. Вместо этого необходимо выбрать 
дополнительные эффекты из галереи «Добавить анимацию». Когда к объекту применено несколько эффектов, в галерее анимации будет выбрано несколько, а не имена эффектов (рис. 6).

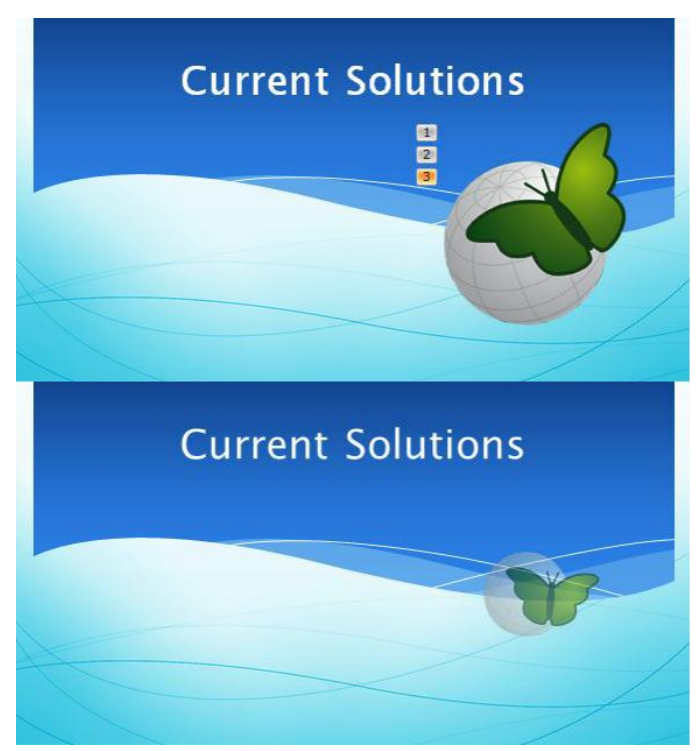

\section{Рис. 6. Градиентное движение бабочек и сфер}

\section{Применение пути движения.}

В то время как такие эффекты, как «Лететь» и «Вылететь» могут в определенной степени управлять движением объекта, траектории движения дадут вам полный контроль. Центр объекта будет следовать траектории движения. Заметим, что существует множество предустановленных траекторий движения и форм, из которых можно не только выбирать необходимые, но и рисовать пользовательский путь. У траектории этого движения есть начало и конечная точка, которые показаны зелено-красной стрелкой (рис. 7).

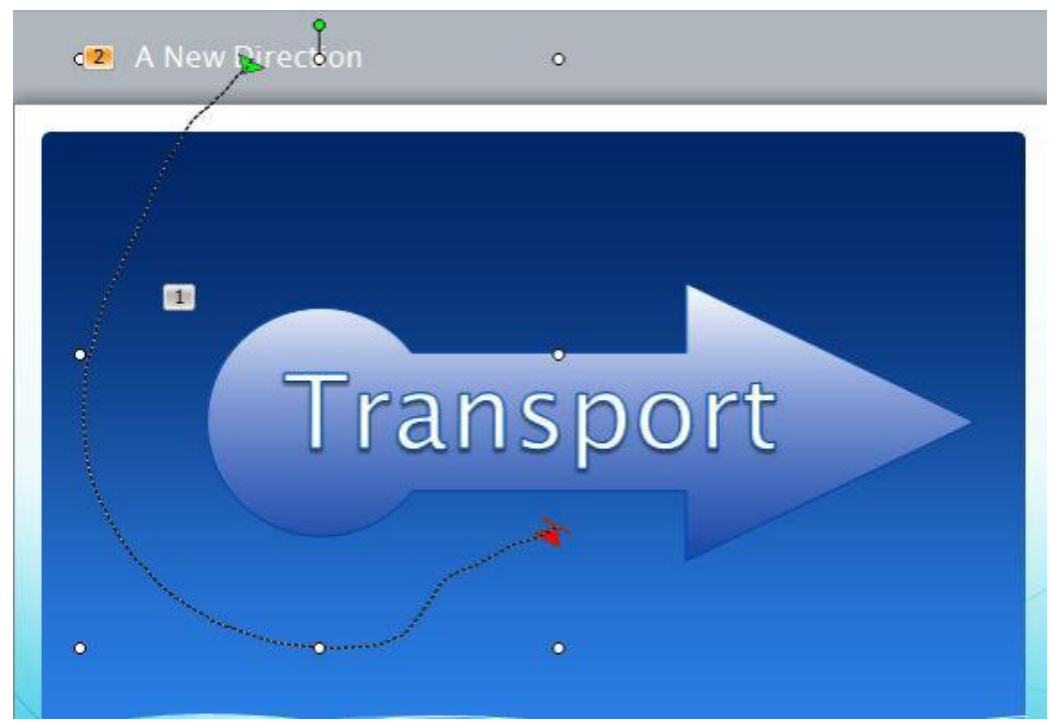

Рис. 7. Путь движения 


\section{Анимационная SMATART графика.}

Анимация SmartArt немного отличается от анимации других фигур и объектов. Во-первых, любые соединительные линии здесь нельзя анимировать по отдельности. Во-вторых, нельзя изменить порядок, в котором отображаются отдельные фигуры в SmartArt. Однако можно выбрать, будет ли анимация применяться к SmartArt в целом, уровень за уровнем и далее (рис. 8).

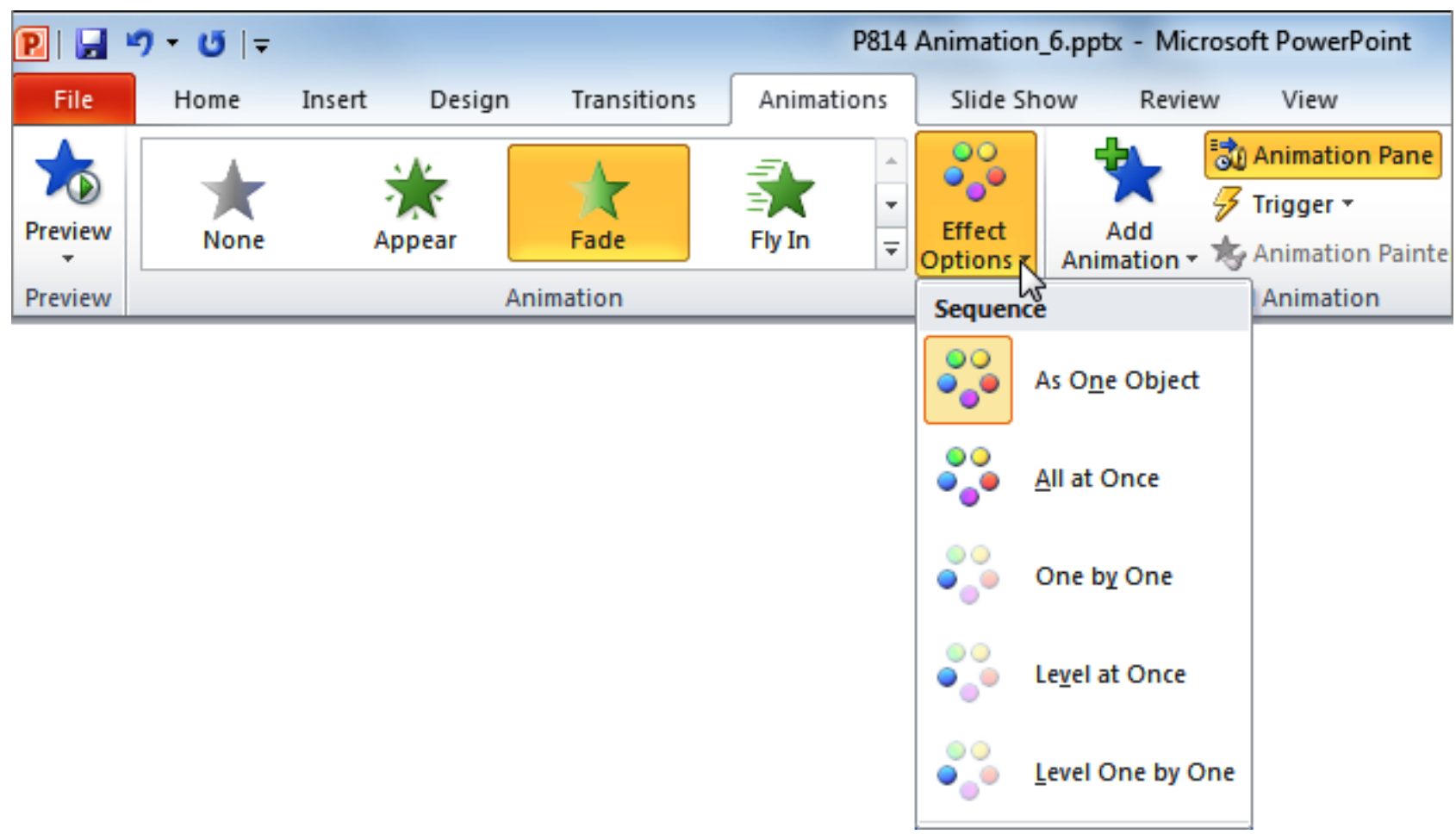

Рис. 8. Анимация SmartArt

\section{Применение слайдовых переходов}

Презентация в PowerPoint, как и история, обычно имеет начало, середину и конец [4]. Чтобы отметить эти моменты можно использовать анимацию в форме Перехода, например, переход к заключительному слайду. Чтобы снова привлечь внимание необходимо использовать анимацию перехода, которая добавит немного больше энергии. Когда откроется панель перехода в PowerPoint, можно заметить, что имеется много различных вариантов на выбор (рис. 9). Итак, использовать анимацию в PowerPoint несложно. Можно сделать для себя такой вывод - вовремя подумать о контексте и времени анимации. Когда дело доходит до анимации, обычно меньше работает лучше, чем больше. 


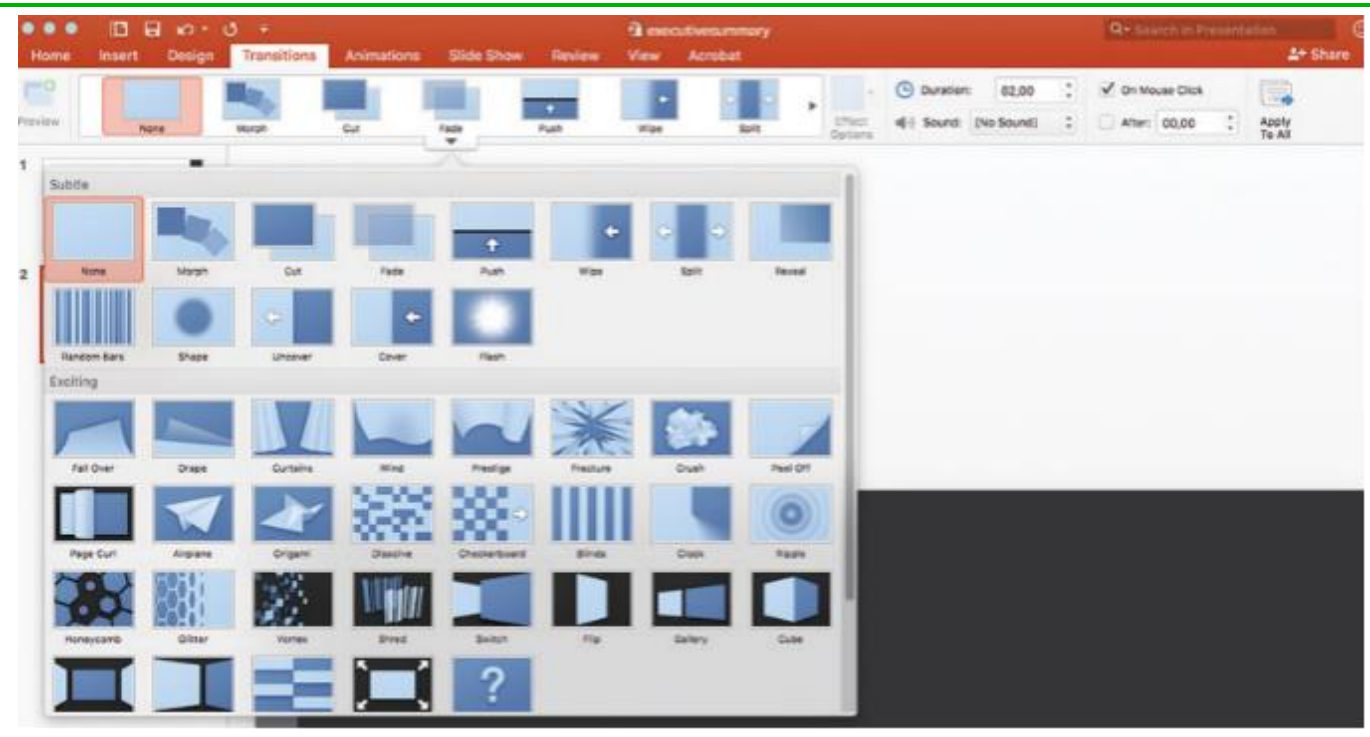

Рис. 9. Разнообразные переходные анимации в PowerPoint

Независимо от того, используется ли программное обеспечение для презентаций преподавателя или для выступлений студента с отчетом программное обеспечение может помочь разработать и усовершенствовать разрабатываемый контент по различным разделам или темам учебной дисциплины для обучающихся различных возрастов, культур и стилей обучения.

\section{Список литературы}

1. Катханова Ю.Ф., Ван Ян. Тенденция развития визуализации информации в образовательной среде. //Преподаватель ХХІ век. 2020. № 1-1. С. 154-158.

2. Катханова Ю.Ф. Корыгин А.И. Анимация в развитии творческого мышления обучающихся. Наука и образование: Сохраняя прошлое, создаем будущее. Сборник статей XXXI Международной конференции. В 2 ч. Ч. 2. Пенза: МЦНС «Наука и Просвещение». - 2020. С. 61-65.

3. Ши Цзиньян, Чен Ган. Непонимание приложения POWERPOINT в классе и его культурный анализ. Информация об образовании Китая (основное образовательное издание). - 2008. - С. 30-32.

4. Лю Юэцзюнь, Проблемы учителей, создающих учебные программы POWERPOINT, являются контрмерами. Информация об образовании Китая (основное образовательное издание). - 2009. С. 26-28.

(C) Ван Инжуй, Д.Д. Аветисян, 2021 